\title{
The design and implementation of smart analysis test bed for the electric automobile storage battery performance
}

\author{
Zhan Huizhen \\ Automotive Engineering institute, Jiangxi University of Technology, Nanchang 330098, China
}

Key words: Storage battery; Electric automobile; Analysis platform; Design

\begin{abstract}
Energy shortage crisis and air pollution are the two global challenges threatening the sustainable development of traditional means of transport---- gas cars. In this case, electric automobiles grow to be the new direction of the automobile's development for its non-pollution, high efficiency, various energy source, simple structure and easy maintenance. In order to make the "heart"--- storage battery highly-efficient, safe and longevous, a series of assistant devices should be adopted to serve it. The charging unit is an inevitable part as the supply of the battery energy. It is found that most storage batteries are damaged by charging. A smart analysis test bed for the electric automobile storage battery performance is designed in the article, which can study and analyze the charge and discharge characteristics of all types of storage battery in the lab. It cuts the research expense, shortens the research time, simplify the procedure and improve the analysis accuracy.
\end{abstract}

\section{Introduction}

The international conference of OPEC estimates that the oil reserves that have been located throughout the world will run out in the next 50 years. It is reported that the pollution of automobile exhaust gas is increasing by over $20 \%$ annually. The nitrogen dioxide produced by exhaust gas do harm to human's health directly and indirectly. The exhaust gas will trigger photochemical pollution, which will do more damage. Los Angels, USA was the first city where the exhaust gas caused photochemical pollution damage. The hazard was the well-known Los Angles Smog Attack.

Energy shortage crisis and air pollution are the two global challenges threatening the sustainable development of traditional means of transport---- gas cars. In this case, electric automobiles grow to be the new direction of the automobile's development for its non-pollution, high efficiency, various energy source, simple structure and easy maintenance. The electric automobile can carry electric energy and ride just as the ordinary cars on the ordinary road. It is dynamic, economical, safe and reliable just like the average IC vehicle. Meanwhile the electric automobile is also of low noise and zero emission of exhaust gas. It is energy-saving easy to maintain and can be charged during the period of electricity trough. The electric automobile, which is run by power storage battery, is considered the green project in the 21 st century. It has been a practical solution to energy shortage crisis and air pollution.

To maintain the safety of the energy in our country, improve the atmospheric environment and reinforce the competitive capability of the automobile industry, the National Ministry of Science and Technology established major special projects for electric automobile in the national " 863 " plan in September, 2001. Starting from the development strategies of national automobile industry, those projects select the new-generation electric automobile technology as the major tendency of China's 
automobile scientific innovation. Enterprises, colleges, universities and scientific research institutions are organized to cooperate with one another. During the "fifteen" period, the industrialization technology platform of electric automobile is emphasized. Some significant breakthrough has been achieved in key unit technology, system integration technology and the whole vehicle technology. In order to gather limited resources to dominate the highest level of the new-generation electric automobiles and to promote the relevant major projects in our country, the arrangement of "three vertical and horizontal plans" is put forward. The horizontal plans include pure electric automobile, hybrid power automobile and fuel cell vehicle, while the vertical ones are battery, dynamo and key components of the control system. It emphasizes to construct the rigorous program for whole vehicle development according with the principles and proposes that the basic policy should be led by the whole vehicle development, along with the combination of key components and related materials and the harmonious development of infrastructure, technology standard and evaluation techniques. As an exploration of the domestic automobile science and technology project, the productization and industrialization of electric automobile major special projects can be guaranteed and realized. Currently, the scientific research fund for the project has been about RMB900, 000,000 more than it should be invested, totaling over RMB25 billion.

The quality of storage battery directly affects the performance index and using effects which are the most important to electric automobiles. At present, the development of storage battery cannot meet the demand theoretically and technologically. Before the battery technology gets some great breakthrough, how to analyze the performance of storage battery efficiently is well worth researching. And the key to the analysis is in what way the storage battery should be experimented to charge and discharge and how the data should be analyzed.

The storage battery is the key part of electric automobiles, whose performance has a direct impact on the vehicle's dynamic characteristics and driving range, so analyzing the characteristics of charging and discharging the battery is rather significant to improve the performance of the electric automobile.

There are many kinds of storage battery can be applied to electric automobiles with different characteristic of charge and discharge. Usually what we care are time, mode, current, voltage and temperature rise for charging and discharging time, temperature rise and cycle index with different currents as well. To solve the problems, a smart analysis test bed for the electric automobile storage battery performance is designed in the article, which can study and analyze the characteristics of charge and discharge in labs, thus reducing the research cost, shortening the research time, simplifying the procedure and improving the analysis accuracy.

\section{Systematic design}

Although there is no fashioned analysis test bed for electric automobile storage battery domestically, the charging and discharging device, the major functional component of test bed, is ready. Based on the equipment of charge and discharge, it can be updated as the analysis test bed for storage battery performance by coordinating with industrial control computer and corresponding systematic software.

There are many types of storage battery that can be applied to electric automobiles, such as nickel storage battery, nickel-metal hydride battery, lithium ion battery, zinc air battery and lead-acid battery. Lead-acid storage battery is always be the first option for electric automobile battery owing 
to its sophisticated manufacture technology, low price, high open-circuit voltage, good high-and-low temperature performance, high efficiency, long floating charge and non-memory effect.

The charge of storage battery should be simple, but because of the problems of polarization, heat emission, etc, the charge and discharge of storage battery is a complex issue. Correct means for charge can lengthen the lifespan of the storage battery. It is found that most storage batteries are damaged because of charging. Thus, it is quite necessary to study the charging means.

In the 1960s, American scientist Math did abundant experimental study over the charging process of the open storage battery and put forward an acceptable charging curve in the premise of lowest gas efficiency.

Currently, each research institution of domestic electric automobiles usually studies and develops the device only for charging or discharging storage battery after selecting the type of storage battery for electric automobile, but there are seldom instruments to analyze the performance of various batteries with different charging means.

The analysis of the performance of storage battery begins with plentiful charge and discharge experiments, so a device which can be used for diverse storage batteries should be designed. The key of the task is to design a device suitable for diverse batteries and different charging means.

The structure of the system should be the control system under the circumstance of Window98, and the design should accord with relevant regulations. Its accuracy must reach or exceed the national standard. The system has appropriate technological layout and scientific monitoring pace, enabling to improve the supervision efficiency and meet the initial demand of performance analysis for the storage battery. The interface adopts full Chinese input, making the operation easy and simple. The external output interface is sealed so as to prevent virus and improve the security of the system effectively. The system can charge and discharge in different manners and analyze the performance as well as file and process the historical data.

It can adjust high voltage $100 \mathrm{~V}-300 \mathrm{~V}$ continuously and current $0-30 \mathrm{~A}$ to charge the battery intelligently.

It can adjust low voltage $10 \mathrm{~V}-30 \mathrm{~V}$ and current $0-100 \mathrm{~A}$ for constant-current charge, constant-voltage charge and impulse quick charge, etc.

It can discharge precisely with the highest current (ZOOA). The system can simulate the discharging current of the battery in different working condition and test the discharge.

It can supervise the charge and discharge performance index of terminal voltage, terminal current and battery temperature as well as the system performance index such as charging voltage, charging current and temperature of major components and parts in time.

The system can deal with emergencies such as outage of power, stop charging and stop discharging by soft and hard means when unusual conditions occur. When working, the system will analyze every index parameter under the supervision of the system software and enable to process abnormal non-interferential signals. Even if the software breaks down, it will press the button "scram" or "dissolve quickly" components to protect the system, strengthening the system's robustness.

The system adopts current time integral method to predict the capacity of the battery. The capacity progress bar is displayed on the working interface. Based on the capacity, whether to continue charging and discharging can be ascertained precisely. The supervision, judgment and control of the capacity can prevent overcharging and over-discharging doing damage to the battery.

The system can record and describe the performance index curve of charge and discharge in time. 
The system can record and store the monitoring data of charge and discharge every time and is able to call out the historical record and print the performance analysis report at any time.

\section{Software design of the system}

The software is compiled with $\mathrm{VC}+6.0$. The operators work on the industrial control computers with touch screen to test the battery's charge and discharge based on actual demands. The control interface is simple, convenient and intuitive following humanized design concept.

According to the charging characteristics of storage battery, input the charging current value and time (at most 8 time quantums) of each phase. After inputting the scheme, click "Add" to reach the history and the scheme is stored to the database. In the list box of the historical data, find the charging scheme you need from the history and click it. The scheme turns blue. Click "Confirm" to get to the working display interface. If the scheme is verified, then click "Confirm" and the system will charge the vehicle in high voltage program as the pre-determined plan requires.

As for constant-current charge, select the check box of constant-current charge, click "Confirm" and then you will enter the working interface. Constant-current charge actually is to charge the vehicle by steps. Input a certain charging current value and time value. When the phase is over, operators can decide whether to continue charging according to the charging time, until the charging ends. High constant-voltage charge is a sub-step of high voltage program charge. Therefore, the control flow diagram is the same.

Here are the steps of charging in high voltage program.

Begin charging. Initialize to the hardware circuit to trigger the charging pilot relay.

Detect whether the hardware functions normally. Yes, then the light turns red. Start the buzzing. Shut down the system and cut the power. Charge ends. Otherwise, continue the next step.

Judge whether the battery's capacity is full. Yes, then move on to the next step. Otherwise, go back.

Judge whether the phase ends. Yes, then the light turns red. Start the buzzing. Shut down the system and cut the power. Charge ends. Otherwise, continue the next step.

Obtain the current values of each phase.

Based on the output voltage values, gather the corresponding current values. Trigger D/A: passage 0 .

Gather A/D: passage 0: current; passage 1: voltage; passage 2: temperature.

Start timer and display in the form of count down.

Calculate the battery's capacity and time that is taken. Open the display progress bar.

Time is up according to the timer? Yes, go back to 4); otherwise, move to the next step. Yes, move to the next step; otherwise, go back.

Detect whether the voltage, current, temperature, etc are normal. Yes, then move to the next step, otherwise, the light turns red. Start the buzzing. Shut down the system and cut the power. Charge ends.

Detect whether the number input passage has signals. Yes, move to the next step; otherwise, the light turns red. Start the buzzing. Shut down the system and cut the power. Charge ends.

Judge whether the battery capacity is full. Yes, the light turns red. Start the buzzing. Shut down the system and cut the power. Charge ends. Otherwise, go back to 10).

In the process of charging, the control and display of time is quite important. Therefore, the system adopts the method of intercepting the operation time in real time to control and display time. 
When the charge starts, a systematic time is intercepted from OnTimer exterior. Then enter OnTimer and intercept another time. The difference between the two intercepted times is the time that charge and discharge lasts.

\section{Conclusion}

The test bed implements adjustable smart charging with high voltage $100 \mathrm{~V}-300 \mathrm{~V}$ and current $0-30 \mathrm{~A}$ and low voltage $0 \mathrm{~V}-30 \mathrm{~V}$ and current $0-100 \mathrm{~A}$ as well as constant-current charging and impulse quick charging, etc. It simulates the discharge procedure of electric automobile storage battery in different working conditions. It can discharge precisely within 0-20, record the parameters such as the voltage, current and temperature, etc and draw the real-time curve. After specific tests, the indicators above have reached the requirement of the design. The system can deal with emergencies like alarming, outage, stop charging, and stop discharging, etc in abnormal working conditions in soft and hard ways. It is showed that the development of such a test bed is advanced, for it integrates charge and discharge, and heavy load discharge, which helps to get various parameters of normal charging and quick charging. It can be applied to the performance research of the charge and discharge for the lead-acid battery as well as storage batteries of other types. When the system parameters set the interface and a mode for charge and discharge is designed, the system can analyze its performance. The test bed is stable, secure, reliable and of higher value for application.

\section{Acknowledgements}

This work was financially supported by the key subject building project (vehicle engineering) of Jiangxi University of Technology.

\section{References}

[1] Jiang D R, Powell W B. Optimal Hour Ahead Bidding in the Real Time Electricity Market with Battery Storage using Approximate Dynamic Programming[J]. arXiv preprint arXiv:1402.3575, 2014.

[2] Chami M, Martinet S, Masse F. High-power lithium-ion storage battery: U.S. Patent Application 14/242,293[P]. 2014-4-1.

[3] Ohashi M, Nishikawa T, Sunahata Y, et al. STORAGE BATTERY CONTROL DEVICE, STORAGE BATTERY CONTROL METHOD, PROGRAM, ELECTRICITY STORAGE SYSTEM, AND POWER SUPPLY SYSTEM: U.S. Patent 20,150,002,102[P]. 2015-1-1.

[4] Yagi S, Ichitsubo T, Shirai Y, et al. A concept of dual-salt polyvalent-metal storage battery[J]. Journal of Materials Chemistry A, 2014, 2(4): 1144-1149.

[5] Khajesalehi J, Hamzeh M, Sheshyekani K, et al. Parallel operating of two energy storage battery systems using quasi Z-source inverter[C]//Thermal Power Plants (CTPP), 2014 5th Conference on. IEEE, 2014: 165-172.

[6] Xue M, Ren R, Wu L, et al. Blood lead levels in lead-exposed workers in storage battery industry: a survey from2011 to 2012 in Hangzhou, China[J]. Zhonghua lao dong wei sheng zhi ye bing za zhi= Zhonghua laodong weisheng zhiyebing zazhi $=$ Chinese journal of industrial hygiene and occupational diseases, 2014, 32(4): 282. 
[7] Tai C L, Cheng C H. Battery storage module and mounting seat: U.S. Patent Application 14/517,927[P]. 2014-10-20.

[8] Nagano H, Takahashi O, Hayashi N. Sealing Member And Storage Battery Temperature Adjusting Apparatus Using The Same: U.S. Patent Application 14/337,922[P]. 2014-7-22.

[9] Skinlo D M, Tsukamoto H, Szyszkowski A, et al. Electric Storage Battery Construction and Method of Manufacture: U.S. Patent Application 14/454,010[P]. 2014-8-7.

[10] Yu H, Fang W, Liu J X. Storage battery cabinet and storage battery system: U.S. Patent Application 14/516,244[P]. 2014-10-16. 